
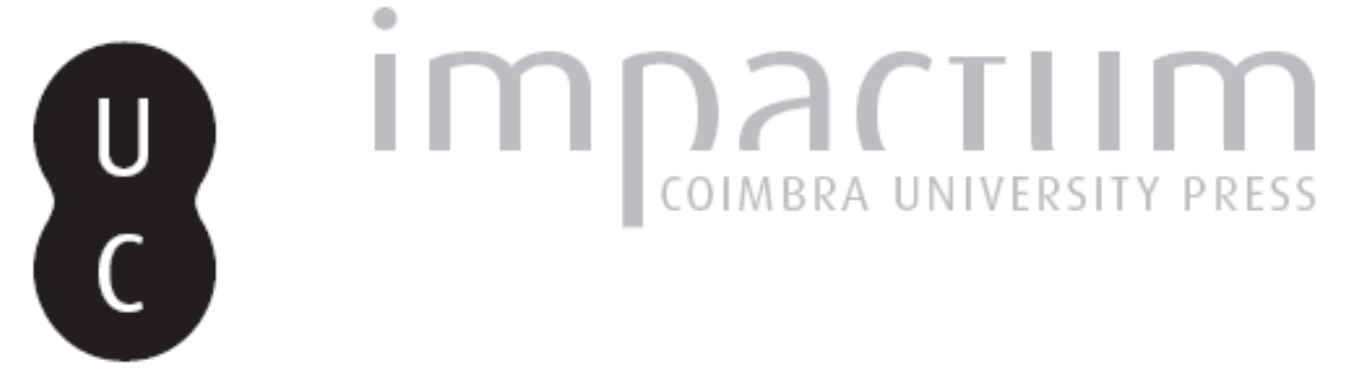

\title{
Filhos, enteados e apadrinhados: discursos, políticas e práticas dos serviços de saúde da Diamang, Angola
}

\author{
Autor(es): $\quad$ Varanda, Jorge \\ Publicado por: CIAS - Centro de Investigação em Antropologia e Saúde \\ URL \\ persistente: \\ URI:http://hdl.handle.net/10316.2/29599 \\ DOI: \\ DOI:http://dx.doi.org/10.14195/2182-7982_29_10 \\ Accessed : $\quad$ 26-Apr-2023 14:00:33
}

A navegação consulta e descarregamento dos títulos inseridos nas Bibliotecas Digitais UC Digitalis, UC Pombalina e UC Impactum, pressupõem a aceitação plena e sem reservas dos Termos e Condições de Uso destas Bibliotecas Digitais, disponíveis em https://digitalis.uc.pt/pt-pt/termos.

Conforme exposto nos referidos Termos e Condições de Uso, o descarregamento de títulos de acesso restrito requer uma licença válida de autorização devendo o utilizador aceder ao(s) documento(s) a partir de um endereço de IP da instituição detentora da supramencionada licença.

Ao utilizador é apenas permitido o descarregamento para uso pessoal, pelo que o emprego do(s) título(s) descarregado(s) para outro fim, designadamente comercial, carece de autorização do respetivo autor ou editor da obra.

Na medida em que todas as obras da UC Digitalis se encontram protegidas pelo Código do Direito de Autor e Direitos Conexos e demais legislação aplicável, toda a cópia, parcial ou total, deste documento, nos casos em que é legalmente admitida, deverá conter ou fazer-se acompanhar por este aviso.

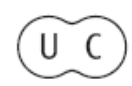




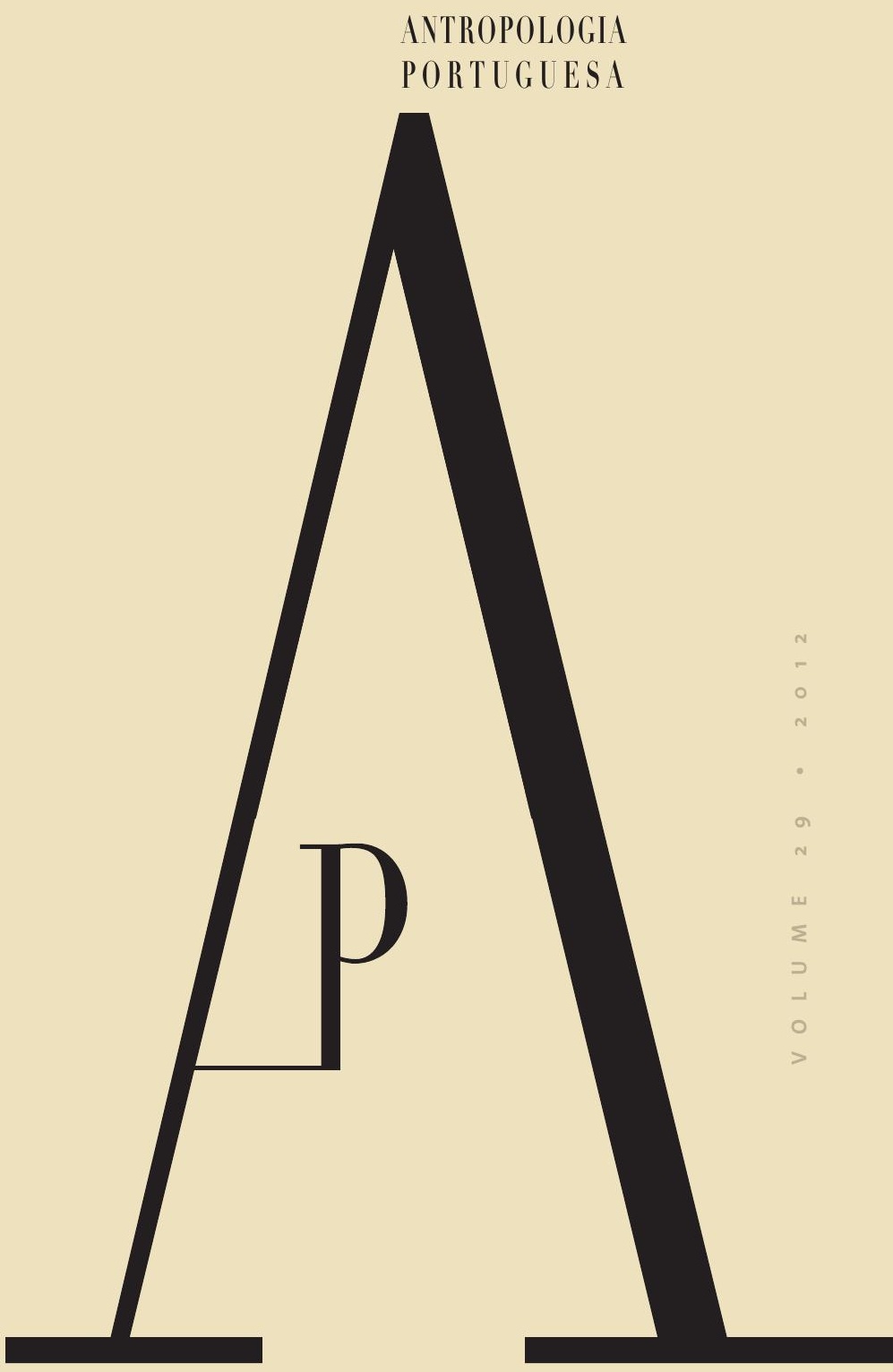

CENTRO DE

INVESTIGAÇ̃̃O

EI ANTROPOLOGIA

E SAÚDE

UNIVERSIDADE

DE COIMBRA 


\section{Filhos, enteados}

\section{e apadrinhados:}

discursos, políticas

e práticas dos serviços

de saúde da Diamang,

Angola ${ }^{1}$

\section{Jorge Varanda*}

jorge.varanda@uc.pt

Resumo Este texto pretende revelar a complexidade da prestação de cuidados biomédicos na Companhia de Diamantes de Angola (Diamang). Intenta-se questionar as representações coloniais de equidade de tratamentos entre Brancos e Africanos por parte dos Serviços de Saúde da Diamang (SSD). A análise ilumina a prestação de cuidados biomédicos diferencial entre expatriados e africanos e como esta era replicada entre africanos. A hierarquia entre os africanos coloca-

\begin{abstract}
This text intends to unveil the complexity of biomedical care under the Companhia de Diamantes de Angola (Diamang). It aims to question the persuasive fictions produced by the Diamang regarding the equity of health care provided by its own health services (SSD). A more in-depth analysis unveils that, as in other mining companies in Africa, it did not provide equal care. More importantly it reveals the existence of a hierarchy of care amidst its African population. The form of engagement
\end{abstract}

\footnotetext{
1 O financiamento para as investigações efectuadas foi possibilitado pela FCT- bolsa pós-doutoramento SFRH/BPD/30439/2006 (2010-2012) e pelo projecto PTDC/AFR/100646/2008 (2010-2012). Agradeço ao pessoal do Museu de Antropologia da Universidade de Coimbra (MAUC), particularmente às direcções, nomeadamente ao Prof. Nuno Porto, por facilitar o acesso aos arquivos. Fica um agradecimento especial a todos os informantes em Portugal e na Lunda por partilharem as suas memórias.
}

* Departamento de Ciências da Vida (DCV), Universidade de Coimbra 
va os trabalhadores no topo, seguidos pelos seus familiares, sendo a pirâmide ocupada pela população sem relações com a produção de diamantes. Subjacentes aos discursos de igualdade de cuidados biomédicos havia também objectivos políticos internos e internacionais, que contribuíam para as reconceptualizações do Terceiro Império Português assim como para a (re)construção dos sujeitos africanos.

Palavras-chave Serviço de saúde da Diamang; cuidados biomédicos; morbilidade e mortalidade; economia política de cuidados biomédicos; colonial; Angola.

Na resposta às críticas produzidas por Gilberto Freyre em Aventura e Rotina, de que a companhia agia segundo regras nórdicas e não luso-tropicais onde a miscigenação era caracterizada positivamente (Freyre, 1954), o administrador-delegado da companhia de diamantes de Angola (Diamang), Ernesto de Vilhena, opunha-se à miscigenação e negava veementemente que a política da companhia fosse racista. Para o último, a política enquadrava-se antes na prática tradicional portuguesa de paternalismo onde todos eram tratados de igual modo, com a mesma benevolência protetora' (Vilhena, 1955).

\footnotetext{
1 O uso que Ernesto de Vilhena faz do termo paternal referindo-se a uma protecção e orientação paternal, ou seja, com uma concepção positiva,
}

- or lack thereof - with the diamond enterprise molded this pyramid which had workers on top, ensued by its relatives and lastly the general population without ties to the company. These discourses on equality of care had ulterior political goals, both in the colonial and international setting. This study is thus relevant to (re)conceptualize the Third Portuguese Empire as well as to better grasp ongoing (re) construction of African subjectivities.

Key words Health service of Diamang; biomedical care; morbility and morbidity; political economy of care; colonial; Angola.

A esta discussão subjaz a ambiguidade sempre presente no primeiro contacto com a Diamang - uma companhia colonial que explorava e cuidava dos africanos. Este sentimento 'perturbador', que permanece quase quatro décadas depois do fim do projecto colonial português, relaciona-se com a força das representações e discursos que afirma(va)m que a Diamang contraria(va) as 'regras' da sociedade colonial (Balandier, 1955: 3-36).

As representações coloniais sobrevivem e são continuamente (re)construídas, atingindo um caráter tão ou mais persuasivo no terreno pós-colonial como num império subalterno acossado pela

difere da concepção negativa presente no contexto anglo-saxónico. 
pressão política da descolonização. Representações como "a Diamang era um estado dentro de um estado"; "era gerida por ingleses"; "os seus Serviços de Saúde da Diamang (SSD) tinham tudo"; "brancos e negros eram tratados de igual modo pelos SSD" são quase ubíquas no senso comum. Esta robustez é consequência da falta de perspectivas críticas, discursos que contrariem o discurso dominante referente à Diamang. Apesar de ter sido a maior companhia do Terceiro Império Português, uma das cinco maiores produtoras de diamantes do mundo, são parcas as referências académicas a respeito desta empresa. Este é, assim, um dos desideratos do texto, contribuir para uma visão mais elaborada sobre a vida na Lunda "da" Diamang e com isso elucidar a veracidade das representações dominantes.

Com base numa análise do dia-a-dia colonial na Lunda, este texto pretende caracterizar a prestação de cuidados biomédicos num canto recôndito no interior do Terceiro Imperio Português. Apesar da retórica referente à equidade na prestação de cuidados de saúde, as diferenças de tratamento entre expatriados e africanos verificadas nos anos iniciais persistiram até ao fim do período colonial.

No entanto, esta característica não torna a Diamang num caso ímpar, aliás, pelo contrário enquadra-a numa norma que é ontologicamente colonial: tratamento diferencial baseado nos caracte- res 'rácicos' individuais. Mas o argumento deste artigo veicula que as classificações da Diamang eram mais complexas, sendo moldadas por conceitos de produtividade, indo assim muito além de simples caracterizações rácicas. Pretende-se pois verificar a existência de hierarquias de atenção sanitária, consequência de uma economia política de cuidados biomédicos, e que no dia-a-dia da Lunda colonial este hiato traduziam-se em doença ou mesmo morte.

O cariz de ligação entre a companhia e o indivíduo (ocidental ou africano trabalhador, seus familiares ou estranhos²) influía no tipo de cuidados de saúde que uma pessoa poderia usufruir. Se entre ocidentais e africanos a companhia aplicava o viés inerente ao ethos colonial, uma análise mais atenta revela a existência, no pólo africano da 'equação racial colonial', de uma organização intra-racial com consequência direta nos cuidados de saúde obtidos e nas enfermidades que se padecia. Ou seja, entre africanos eram os trabalhadores/mineiros que recebiam melhores cuidados biomédicos, seguidos das respectivas famílias enquanto a população local, sem qualquer afiliação produtiva com a Diamang, i.e. estranhos, era menosprezada.

\footnotetext{
2 Classificação da Diamang relativa a indivíduos e/ ou comunidades localizadas fora das áreas industriais/coloniais da companhia e que não apresentavam qualquer função produtiva directa com a mineração ou seus trabalhadores.
} 
Metodologicamente, por forma a revelar a complexidade da prestação de cuidados biomédicos por parte dos SSD, recorre-se a triangulações metodológicas de uma etnografia de arquivo (Porto, 2002) executada com recurso a análises de fontes primárias com leituras a contra/ favor do pêlo (Prakash,1994; Stoler, 2009), complementada com recursos à história oral efectuada em Portugal e Angola, e a análises quantitativas.

A acção dos SSD é dividida em três fases para melhor apreender-se a prestação de cuidados de saúde sobre as diferentes populações presentes na área da Diamang. Na primeira fase, 1917-1933, a prestação de cuidados biomédicos é caracterizada por uma clara falta de meios, infra-estruturas e pessoal de saúde. Os serviços tentam colmatar as dificuldades mais prementes que colocam em perigo a produção diamantífera. A medicina praticada é eminentemente curativa, centrada nos empregados europeus com atenção esporádica aos casos mais problemáticos dos trabalhadores africanos.

Em 1933 o aumento da incidência da Tripanossomíase Humana Africana (doença do sono) para níveis epidémicos despoleta a primeira re-organização dos serviços. Os dois ramos da Diamang que lidavam com a saúde, SSD e Missões de Profilaxia da Doença do Sono (MPDS), são agrupados, com o último a ficar sob a alçada do primeiro. Neste estádio, 1934-1956, os serviços quebraram com o espartilho da medicina de enclave (Arnold, 1993): primeiro através da sistematização da actuação das missões ambulantes, depois pela ocupação sanitária da região efectuada através da construção de unidades sanitárias secundárias e terciárias em áreas rurais. Estas práticas, em conjunto com outras políticas sanitárias, permitiram o reforço da atenção a trabalhadores, às respectivas famílias e, lentamente, aos estranhos.

O contexto de guerra colonial que acompanha o terceiro período, 19571975, provoca um decréscimo do pessoal de saúde com formação superior, pessoal expatriado, o que perante o aumento de população, trabalhadores, unidades sanitárias e actos de assistência reflecte-se num decréscimo na qualidade dos cuidados biomédicos. Apesar disso, é neste período que se consolida a assistência biomédica a toda a população e que ganham relevância as acções de visibilização dos programas de saúde pública, particularmente em palcos políticos internacionais onde a descolonização era acerrimamente discutida (Shapiro, 1983). As representações de um colonialismo atento à saúde dos trabalhadores, famílias e populações locais apresentadas em fóruns internacionais não tinham tradução num acesso equitativo à terapêutica para todos os que habitavam a Lunda da Diamang. 


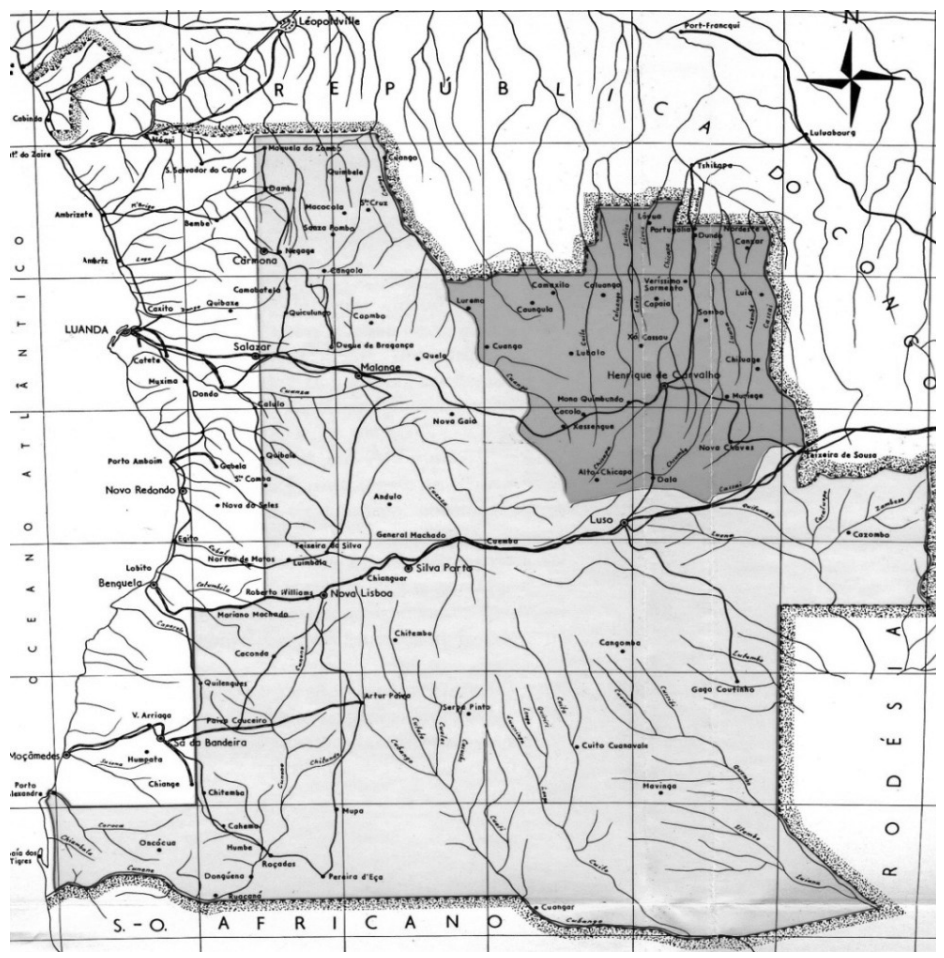

Figura 1. Mapa de Angola. O cinza claro indica a zona concessionada à Diamang e a cinza escuro a área de operação e recrutamento exclusiva. O centro Administrativo da Companhia é na cidade do Dundo.

Apesar das disposições contratuais estabelecidas entre a Diamang e o governo colonial e de uma retórica de cuidados similares para populações diferentes, prevaleceu durante quase seis décadas uma hierarquia na prestação de cuidados biomédicos entre ocidentais, africanos e entre as várias classificações impostas pela Diamang entre estes últimos. Uma constante que reflectiu-se na morbilidade e causas de morte.

\section{A companhia de diamantes de Angola - Diamang}

No início do século XX prospectores da empresa Belga Forminiére (Société International Forestière et Minière du Congo) descobriram diamantes nos territórios contíguos ao nordeste Angolano, circunscrição ${ }^{3}$ do Chitato, distrito da Lunda (Figura 1).

\footnotetext{
3 Sub-divisão administrativa normalmente do interior usualmente apresentando pouca população ocidental.
} 
Como corolário formou-se em 1911 a PEMA (Pesquisas Mineiras de Angola) para mapear jazigos de diamantes ${ }^{4}$. Em 1917 dá-se a génese da Diamang, empresa criada para explorar os jazigos entretanto descobertos pela extinta PEMA.

O contrato da Diamang assinado com o governo em $1921^{5}$ atribuía à companhia direitos de exploração de diamantes em quase toda a colónia, concedia a exclusividade da actividade comercial na área da sua concessão, isentando-a da maioria dos impostos. Como contrapartida a companhia auferia $40 \%$ dos seus lucros ao estado e responsabilizava-se pela acção civilizadora que incluía a prestação de cuidados de saúde à população local - trabalhadores ou não.

A mineração era do tipo aluvião, efectuada essencialmente com o recurso a força braçal local, isto é baseada em políticas de baixo custo. Em 1920 a Diamang e os seus serviços de saúde operavam nos $20.000 \mathrm{~km}^{2} \mathrm{com} 20 \mathrm{em}$ pregados brancos e 2.300 trabalhadores indígenas. No final do período colonial a área dos SSD laborava numa área superior a $50.000 \mathrm{~km}^{2}$, mais de metade da área da metrópole política, tendo sob a sua

\footnotetext{
4 Sobre a relação entre Forminière e Diamang desde a sua génese até aos anos de 1940 ver Varanda (2011); para história oficial da companhia Belga ver Forminière (1956).

5 Para informação mais detalhada sobre a companhia ver Porto (2009), Varanda (2007).
}

alçada cerca de 135.000 pessoas, 25.000 das quais eram trabalhadores africanos. A produção de diamantes e os lucros apresentaram um crescimento similar. Em 1921 os 106.719 quilates produzidos renderam $£ 320.279$, sete anos depois a produção atingia 237.511 quilates, dez vezes mais que a exploração de Kleinzee na Namíbia (Carstens, 2001), aumentando para 2.500.00 quilates em 1972 com um valor de mercado superior a $£ 28.000 .000$ (Varanda, 2007).

As características de independência dos SSD face aos serviços de saúde estatais, Serviços de Saúde e Higiene de Angola (SSHA), o uso da ciência e da inovação em termos de práticas e programas de saúde pública ${ }^{6}$, e a capacidade financeira da Diamang contribuíram para a implementação de um programa de ocupação sanitária quase duas décadas antes da generalidade de outros serviços de saúde activos na colónia.

${ }^{6}$ Como o objecto do texto não é a saúde pública per se, mas antes história de acções colectivas em relação à saúde de dois tipos de populações específicas, não se discute em profundidade as alterações do conceito de saúde pública. Para mais informações sobre esta temática ver Porter, 2005 [1999].

Expressão corrente nos SSD e SSA, referindo-se à expansão dos serviços de saúde, através de meios de medicina curativa e preventiva, com a intenção de cobertura de uma determinada área, bem como toda a população presente nesta área. 


\section{Medicina de enclave - 1917-1933}

No início a Diamang deparou-se com uma região despida de estruturas coloniais. Esta ocupação incipiente experenciada pela companhia no início da laboração teve impacto directo na saúde de empregados e trabalhadores (ocidentais e africanos, respectivamente). Tal era tangível na ausência de infra-estruturas básicas, redes de transporte, instalações e na natureza 'não-pacificada' das populações locais ${ }^{8}$. Os problemas estruturais traduziam-se em falta de habitações, saneamento básico, dificuldades em atingir a segurança alimentar, acompanhados pela ausência de uma divisão de saúde bem estruturada e com meios humanos e técnicos adequados.

Os empregados, a maioria expatriados não-portugueses, quando enfermos, recorriam a uma caixa de primeiros-socorros, sem instruções, mas com medicamentos e material hospitalar para se automedicarem (Parkinson, 1962) $)^{9}$. Os trabalhadores africanos perante problemas de saúde recorriam a terapêuticas tradicionais. Somente face à persistência dos problemas os africa-

\footnotetext{
8 Sobre as revoltas existentes na Lunda até a meio dos anos de 1920 ver Pélissier (1986).

9 Diamang replicava acções da sua "companhia-irmã" (Forminière), fornecendo uma caixa de metal com medicamentos para ser usado em emergências médicas, embora sem instruções algumas. O engenheiro Parkinson trabalhou para a Diamang entre 1923 - 1934.
}

nos socorriam-se, em última instância, à biomedicina. Nesse momento, estes indivíduos deparavam-se com estruturas de saúde rudimentares, ou mesmo com a falta de instalações da companhia para o fornecimento de cuidados biomédicos. Assim, era comum recorrerem frequentemente aos empregados expatriados para receberem tratamentos (Parkinson, 1962). Aos olhos ocidentais, engenheiros, chefes-de-mina ou capatazes, ou mesmo pessoal de saúde, esta errância por várias terapêuticas era vista negativamente. Esta itenerância era considerada como exemplo de irracionalidade e/ou como tendo objectivos ulteriores, por exemplo, o término antecipado do contrato. Estas primeiras percepções contribuiriam fortemente para representações das cinco décadas seguintes de irracionalidade e de "culpar a vítima" perante qualquer problema ${ }^{10}$.

Somente a meio da década de 1920 se iniciou de forma mais concreta o processo de criação do serviço de saúde - contribuindo nesta altura os dois ramos da saúde - SSD e MPDS - que operavam de forma independente. Foram contratados médicos e enfermeiros, e em 1926 os serviços já eram compostos por três médicos, dez enfermeiros

\footnotetext{
10 As respostas dos Africanos aos problemas de saúde são os tijolos para as representações coloniais posteriores sobre os grupos étnicos ou africanos em geral, ver Vaughan (1991); Packard (1987, 1989, 1993).
} 
portugueses e algumas dezenas de auxiliares Africanos entretanto formados pela companhia"1. Dito isto, a atenção sanitária nos primeiros anos de actividade centrou-se eminentemente nos expatriados, só se expandido para trabalhadores em situações específicas. A dependência direta dos Serviços de Saúde da Direcção Técnica da Lunda (DTL) fazia com que as políticas e práticas pelos SSD tivessem particular ênfase nos atores intimamente relacionados com a produtividade.

A companhia montou diversos hospitais, dispensários e postos sanitários nas áreas mineiras de Cassanguidi, Chingufo e Maludi. Este padrão de proximidade geográfica entre formações sanitárias e minas persistiria até à independência, e indiciava a ordem dos escalões na hierarquia de cuidados biomédicos. Dito isto, as instalações sanitárias existentes apresentavam inúmeros problemas, por exemplo, os hospitais, amiúde desenhados por médicos que também dirigiam a construção, eram pequenos, de construção simples, apresentando enfermarias com capacidade para cinco doentes ${ }^{12}$. Em 1923 o engenheiro, G.H. Newport, notava que os hospitais do Dundo, Cassanguidi e Maludi, feitos de lama e madeira, estavam tão depauperados que deviam

\footnotetext{
1 Dr. Carvalho "RAS 1926", pasta 126B,9-10, MAUC. 12 Dr. Baptista "RS Junho 1925", pasta 126B,9-10, MAUC.
}

ser reconstruídos ${ }^{13}$. Uma tarefa difícil quando faltavam materiais de construção, como ocorreu em 1924 com os trabalhos nos hospitais do Dundo, Maludi e Luaco. Em 1926 foi construído o Hospital central no Dundo. Como referência principal dos SSD, esta instalação era feita de tijolo com telhado de zinco, apresentando três enfermarias com 52 camas e casas de banho com chuveiros, cozinha e incineradora para lixos hospitalares. A divisão racial nos cuidados de saúde era tangível na separação entre áreas para ocidentais e africanos, presente na arquitetura hospitalar. A ala europeia incluía ainda área para consultas, operações e exames laboratoriais. Os seis edifícios circundantes eram usados como enfermarias e/ou quartos de isolamento para doentes africanos com doenças infecto-contagiosas ou dermatológicas ${ }^{14}$.

A localização do hospital principal no centro administrativo longe das áreas mineiras, situadas a mais de cem quilómetros de distância, indicia o viés na provisão de biomedicina para ocidentais, secundarizando os cuidados médicos a trabalhadores africanos. Problemas estruturais como a falta de estradas e pontes, conjugados com um número insuficiente de pessoal de saúde e meios de

13 Carta, 16/11/23, de G.H, Newport para administração, pasta 84K3-4o, "Ocupação e Diversos,", 1/8/23 - 30/11/23.

14 Dr. Vasques de Carvalho "RAS 1926": 8, pasta 126B,9-10, MAUC. 
transporte, limitavam as visitas regulares às minas, agudizando o cariz racialista na prestação de cuidados biomédicos. O contrato entre a Diamang e o estado colonial esclarecia que os trabalhadores e as populações locais seriam objecto da atenção dos SSD, mas a medicina enclave praticada pelos SSD e MPDS definia os expatriados como foco primordial de atenção.

Lentamente a Diamang expandiu a sua administração sob o território recorrendo aos SSD e MPDS. Em 1930 as mais de três dezenas de instalações sanitárias, dispensários e postos de socorro estavam espalhadas por minas e zonas urbanas. Dezenas de auxiliares africanos, formados localmente, efectuavam actos de assistência de natureza simples, redireccionando os casos mais problemáticos para dispensários e hospitais para serem assistidos por enfermeiros ou médicos, respetivamente. No papel, os SSD apresentavam um rácio de um médico para 1.750 Africanos e uma cama por 34 indivíduos, mas as condições precárias e de exiguidade nestes últimos empurravam pacientes locais a dormirem ao relento nas áreas contíguas do hospital ${ }^{15}$. Nos anos 20 nem o pessoal de saúde europeu escapava, com o pessoal de enfermagem do Dun-

15 Dr. Almeida Sousa, 4/12/1930 "MPDS Relatório No 2", pasta Direcção Administrativa - Serviço de Saúde, Relatórios Mensais - Agosto/1926 - Dezembro/1931, MAUC. do a ficar alojado no edifício principal, onde amiúde tinham doentes ocidentais internados nos seus aposentos.

Durante os anos iniciais os SSD não tinham capacidade para providenciar cuidados biomédicos a trabalhadores, assim, estes eram relegados face aos empregados, somente quando a incidência de doenças e mortes ameaçava afectar a produção diamantífera eram estes alvos de atenção. Em 1918-1919 a gripe que varreu África provocou um impacto muito negativo nos africanos a trabalharem no Chitato. Em 1921 a alta mortalidade entre trabalhadores e a falta de pessoal de saúde qualificado forçou a Diamang a recorrer aos elementos dos serviços de saúde da Forminière, nomeadamente do médico-chefe Dr. Gillet. Foi este médico que identificou a doença que dizimava a força de trabalho. No ano seguinte o mesmo médico relatava que os problemas que se relacionavam com a falta de segurança alimentar e a ausência de rede familiar ou social de suporte tinham efeitos delatórios directos sobre a saúde dos mineiros ${ }^{16}$. A estes factores juntavam-se as condições de trabalho e de vida proporcionada pela Diamang que eram visíveis nos corpos debilitados dos mineiros,

16 Carta 4/1/22 de Millard K Shaler, F Van Brée Bruxelas para Lisboa, com relatório Dr. Gillet, pasta 126B,9-10, MAUC. 
empurrando muitos para a deserção, para hospitais ou para o cemitério ${ }^{17}$.

$O$ viés presente nos cuidados médicos era palpável também nas enfermidades que afectavam as diferentes populatrabalhadores Africanos eram a malária, os problemas respiratórios e a influenza, as doenças digestivas e intestinais, a astenia, os traumas e os ferimentos relacionados com o trabalho mineiro, as doenças venéreas, a varíola e os problemas de pele. Os problemas respiratórios representavam cerca de $20 \%$ de todos os problemas de saúde enquanto as disenterias e diarreias eram responsáveis por cerca de $10 \%$ das mortes ${ }^{18}$. Enquanto isso, problemas intestinais e doenças venéreas eram as principais maleitas a afetarem europeus, apresentando estes taxas de mortalidade residuais quando comparadas com as dos trabalhadores.

Como implícito no relatório Ross (Ross, 1925), trabalhar para a Diamang era um perigo para a saúde, no entanto, para os responsáveis dos SSD a culpa era das vítimas. Para o médico-chefe, Dr. Vasques de Carvalho, o pluralismo terapêutico praticado pelos africanos e a falta de higiene nas aldeias e postos contribuíam

\footnotetext{
17 Situações similares foram descritas em diversos contextos coloniais: Africa do Sul, Packard (1989); Rodésia do Sul, van Onselen (1976); Rodésia do Norte, Perrings (1977, 1979); Congo Belga, Lyons, (1991).

18 Dr. Vasques de Carvalho, "RS Dezembro 1930", pasta 126B,9-30 MAUC.
}

para uma maior incidência de problemas pulmonares ${ }^{19}$. O facto das condiç̧̃es de vida (alojamento, alimentação e saneamento) e de trabalho (vestuário e segurança no trabalho) serem omitidos nos relatórios de saúde, e da higiene nas aldeias dos trabalhadores contratados ser da responsabilidade dos SSD até 1937, ano em que o Serviço de Propaganda e Assistência à Mão-de-Obra Indígena é criado ficando responsável por estas acções, não mereceram apontamento do médico-chefe. O discurso veiculado no início da laboração, frequentemente por chefes-de-mina, é posteriormente sancionado por discursos biomédicos e replicar-se-ia até à independência: a culpa é dos africanos vítimas de doenças e acidentes.

Apesar da persistência de doenças entre os trabalhadores e a negligência da companhia para com a população local, o governo continuava a celebrar a acção dos serviços médicos. O governador-geral da colónia, Coronel de Infantaria Eduardo Ferreira Viana, numa visita à Lunda exaltava o trabalho da Diamang pelas 'excelentes instalações dos serviços e assistência cuidadosa ao indígena em todo o seu território' ${ }^{20}$. Em 1933 o aumento rápido da incidência de doença do sono mostrava a fragilidade

\footnotetext{
19 Dr. Vasques de Carvalho, "RAS, 1926":1-13, pasta 126B,9-10, MAUC.

20 BOA (Boletim Oficial de Angola), nº. 43 II serie, 27 de Outubro, SGL.
} 
do modelo de prestação dos serviços de saúde, forçando a reorganização dos dois serviços da companhia. Em 1934 os dois ramos, SSD e MPDS, fundiram-se, ficando o chefe dos SSD, Dr. Vasques de Carvalho, com a tutela do serviço de saúde.

\section{Recomeçar no mato - 1934-1957}

O perigo de uma epidemia e os possíveis efeitos para a produção diamantífera obrigou os SSD a alterar os programas e as práticas de saúde pública. As zonas rurais começaram a ser objecto da acção dos SSD. Esta mudança verificou-se na expansão dos serviços para áreas rurais, primeiro com as MPDS, seguindo-se com o estabelecimento de instalações permanentes, que incluiriam maternidades. Para esta transformação contribuiu também a mudança da Direcção Técnica em Direcção Geral da Lunda (DGL) e o seu primeiro director geral Tavares Paulo. Este outorgou uma maior ênfase a políticas sociais para populações locais, em detrimento da visão eminentemente técnico-produtiva existente ${ }^{21}$.

Estas novas acções de saúde pública, que englobavam uma relação mais estreita com autoridades locais levada a cabo pelo pessoal auxiliar, diferenciavam os

21 Albuquerque, entrevista 15/12/2004; Dr. David, entrevista 27/01/2004.
SSD de outros serviços de saúde na colónia - estatais ou privados -, SSHA, e, por exemplo, Caminhos-de-ferro de Benguela (CFB) ou Sociedade Agrícola do Cassequel (Cassequel) (Esteves, 1999; Ball, 200322).

Entre as décadas de 30 e 50 o crescimento da companhia foi exponencial. 0 aumento do número de explorações mineiras requeria uma maior mecanização das explorações ou uma maior mão-de-obra, mas a política da companhia, face ao custo reduzido da mão-de-obra sob o regime de trabalho forçado e os custos de mecanização no interior de África, privilegiou a segunda (Cleveland, 2008). Em 1935 contabilizavam-se 7.233 trabalhadores e 125 empregados, aumentando em 1955 para 19.736 trabalhadores, 7.278 dos quais contratados acompanhados por $2.073 \mathrm{fa}$ miliares e com cerca de 393 empregados e 580 parentes (Varanda, 2007).

A maior atenção a áreas do interior era palpável na expansão dos SSD para zonas mais afastadas, num território então de $28.000 \mathrm{~km}^{2}$, e pelas instalações hospitalares construídas: hospital-dispensário em Facaúma e novos dispensários nas novas áreas rurais dos postos administrativos de Lóvua, Sombo, Cachimo e Luia.

22 Nas décadas de 1930 e 1940 os serviços de saúde estatais, SSHA, assim como os privados CFB Cassequel estagnaram replicando-se ainda na comparação com exemplos relativos a outras colónias da África como Gana, África do Sul, Namaqualand e Sudão. Ver para os outros territórios coloniais Addae (1998), Packard (1989), Cartens (2001), Bell (1999), respectivamente.

151 
Este investimento estendia-se à qualidade das instalações de saúde, usando-se o tijolo e cimento em detrimento do adobe nas obras de melhoria realizadas nos hospitais de Andrada, Maludi, Cassanguidi. Para acomodar os programas materno-infantis, intimamente relacionados com a reprodução da força de trabalho, surgem as primeiras instalações pediátricas e maternais na década de 40 nos principais hospitais: Dundo, Andrada, Cassanguidi e Maludi. Em 1955 os SSD tinham acrescentado a estes hospitais o hospital-dispensário de Facaúma, cinco depósitos de medicamentos, e alargado a rede de postos de primeiros socorros nas zonas rurais e mineiras ${ }^{23}$. No entanto, a actividade mineira continuava a ser $\mathrm{o}$ vetor orientador desta expansão.

O número de médicos aumentou de três em 1936, centralizados nas explorações mineiras, para o máximo de 14 médicos em 1955, estando três distribuídos pelas equipas móveis de saúde que percorriam aldeias. No entanto, o pessoal europeu de enfermagem não replicava este crescimento, pois dos 10 enfermeiros e uma parteira em 1936 aumentou para 24 enfermeiros europeus, quatro destes mulheres e uma parteira

23 Os hospitais mais importantes (Dundo e Andrada) tinham bloco operatório com ar-condicionado, cozinhas, refeitórios, lavandarias, novos instrumentos como raios- $X$, radioscopia, ultravioleta, ultra-som, máquinas de diatermia e electrocardiogramas. Sobre as redes extra-imperiais que a companhia acedia para fornecer os SSD ver Varanda (2010). em $1957^{24}$. Embora alguns trabalhassem nas campanhas móveis e dispensários mais importantes, o parco crescimento destes profissionais relacionava-se com a política da africanização do serviço de saúde. O quadro auxiliar africano passou de 14 'enfermeiros' e 35 auxiliares em 1936 para um enfermeiro africano certificado, 149 auxiliares de saúde e 389 ajudantes em 195525. As 'traduções' da prática da biomedicina nas campanhas móveis e formações sanitárias menores espalhadas pelo 'mato' contribuíam para uma melhor aceitação, e em paralelo para uma redução dos gastos da Diamang com os recursos humanos de saúde ${ }^{26}$.

No entanto, o modelo do sistema de saúde pública da companhia permanecia urbanocêntrico. A distribuição dos profissionais de saúde com formação superior (europeus) indiciava que os melhores cuidados de saúde eram prestados nos centros urbanos, permanecendo direccionado para ocidentais e suas famílias, seguindo-se os trabalhadores da companhia. A geografia da produção de diaman-

24 Dr. Vasques de Carvalho "RAS, 1936",p.2, pasta 126B,9-4으, Serviços de Saúde (Relatórios Médicos) de 1/8/33 - 30/9/37, MAUC.

25 Os ajudantes eram de ambos os sexos estando dispersos por vários serviços: postos sanitários, equipas móveis contra a doença do sono e materno-infantis, e laboratório.

26 Sobre o papel das enfermeiras como 'tradutoras' culturais para a melhor aceitação da biomedicina, ver Hunt (1999); Lyons (1991). 
tes, a origem racial e o tipo de relação com

a Diamang ainda garantia que o acesso a cuidados biomédicos não era igual para todas as populações - ocidentais, trabalhadores, respectivas famílias e estranhos. Estas condições criavam uma 'geografia de saúde'27, ou seja, áreas onde a saúde comunitária era influenciada directa ou indirectamente pelas condições de vida e o acesso à medicina preventiva e terapêutica. Esta 'geografia de saúde' traduzia-se numa morbilidade e mortalidade diferencial entre as várias populações que viviam sob a égide da Diamang.

A persistência da malária na região, a qual em 1945 o Dr. Picoto descrevia como sendo hiper-endémica, relacionava-se com a natureza não sistemática e diferencial dos programas: em paralelo à profilaxia medicamentosa (empregados e trabalhadores), as acções anti-vectoriais centravam-se unicamente nos centros urbanos. ${ }^{28}$

A persistência assustadora das doenças de índole respiratória como maior causa de morte entre africanos de 1935 e 1955 e de doenças intestinais relativamente à morbilidade relacionava-se com as más condições de vida e de trabalho proporcionadas pela Diamang: No que concerne às últimas, os SSD elaboraram

\footnotetext{
27 Utilizo este termo referindo-me à saúde como conceito espacial teórico presente numa 'ocupação' sanitária do território. Fica assim de parte qualquer caracterização do termo como conceito relacionado com o bem-estar de indivíduos ou populações.

28 Dr. Picoto "RAS, 1945", p. 12, pasta 126B, 9-60; Dr. Picoto "1955 RAS", pasta 126B, 9-10॰, MAUC.
}

programas curativos com tratamentos em massa efectuados no exame de contratação e nas inspecções às minas; no entanto, a falta de investimentos na melhoria das condições de vida e laboração dos trabalhadores, em termos da alimentação e água potável, alojamento, saneamento básico, replicava o ciclo vicioso destas doenças ${ }^{29}$. A influência da falta de condições de alojamento, dureza do trabalho mineiro, carência de alimentação e de indumentária eram preteridas, enfatizando, ao invés, a caracterização biomédica dos corpos indígenas como frágeis, com sistemas imunológicos fracos e dietas inadequadas ao trabalho mineiro e ao clima local ${ }^{30}$.

Embora as infecções sexualmente transmissíveis (ISTs) não fossem um problema relativamente aos dias de trabalho perdidos ou como causas de morte, simbolicamente não podiam ser negligenciadas. A miscigenação racial durante as décadas de 20 e 30 era vista como uma tautologia (Castelo, 1998). Assim, em 1936 é pedido de forma confidencial ao Dr. Mottoulle para inves-

29 Dr. Picoto, "RAS, 1935", p. 3, pasta 126B,9-40; Dr. Picoto, "RAS, 1955", p.16, pasta 126B,9-10, MAUC.

30 Similar ao que Packard descreve para a situação das empresas mineiras da África do Sul a teoria do solo virgem (virgin soil) que enfatizava incapacidade de adaptação à vida industrial moderna como sendo algo biológico numa primeira fase, para ser considerado algo cultural, levando consequentemente a uma maior estigmatização dos africanos e da sua cultura (Packard, 1987, 1993). 
tigar a extensão do problema já que os expatriados não recorriam ao SSD com receio de represálias por parte da companhia. A formalidade dos espaços e corpos separados era desrespeitada na noite colonial. Apesar da dificuldade em definir a incidência de doenças como a sífilis, a gonorreia e a blenorragia no primeiro período, os relatórios dos SSD apontam que em 1945 os exames efectuados somente a contratados revelavam mais de $12 \%$ de positivos, uma percentagem que diminuiu para $9 \%$ em 1955 ${ }^{31}$. A dificuldade em debelar ou em evitar transgressões corpóreas entre dominadores e dominados era 'compensada' pela produção de discursos biomorais sobre os africanos e por representações coloniais persistentemente em disjunção com a realidade, estando perceptíveis na resposta de Vilhena às críticas de Freyre sobre a falta de luso-tropicalismo na Diamang, referindo o administrador-delegado que: brancos e africanos não deviam de partilhar a mesma cama (Vilhena, 1955: 39).

Embora nesse ano o Dr. Picoto observasse que havia expatriados hospitalizados devido à malária, febre, gripe, doenças intestinais e ISTs, estes apresentavam taxas muito baixas inferindo sobre a importância das condições de vida e de trabalho, bem como as políticas dos SSD para o bem-estar. Em

31 Dr. Picoto, "RAS 1955", pp.19-21, pasta 126B,9$-10^{\circ}$, MAUC. termos de morbilidade os expatriados e africanos partilhavam algumas doenças - malária e doenças respiratórias e ISTs -, mas com uma incidência diferencial vincada. No que concerne às causas de morte este hiato surgia ainda mais pronunciado: os ocidentais tinham maior probabilidade de falecerem num acidente de carro do que de doença.

A expansão dos serviços de saúde pública foi conceptualizada para criar "zonas livres de infecções", com objectivo de monitorizar a reprodução da força de trabalho, atentar à transferência indirecta dos custos de saúde, mas mantendo sempre o desiderato de aumentar a produção diamantífera. Subjacente à maior atenção aos trabalhadores, suas famílias e aos estranhos, verificada durante este período estava uma hierarquia diferencial de cuidados, com as famílias dos trabalhadores a apresentarem 50\% mais hospitalizações que a população local. Só no final dos anos 50 a Diamang fornecia cuidados biomédicos a estranhos, cumprindo assim as obrigações contratuais. Esta franja populacional 'não- produtiva' permaneceu invisível durante a maioria deste período apresentando, por exemplo, apenas 79 diagnósticos em 1935 e sendo atingidos mortalmente por doenças que não matavam trabalhadores como a doença do sono ou varíola ${ }^{32}$.

32 Dr. Picoto, "RAS 1935", pasta 126B, 9-40, MAUC. 
O facto de estas mortes serem evitáveis enfatiza a ideia de que os africanos só procuravam a biomedicina quando a doença já estava num estado avançado e quando todas as outras tentativas terapêuticas tinham falhado (Parkinson, 1962: 82).

O baixo número de indivíduos rurais a procurarem os serviços era revelador do sentimento de desconfiança face à biomedicina. Os SSD tentavam demonstrar o valor da biomedicina através de "actos espectaculares de cura", como cirurgias que apresentassem resultados rápidos e "palpáveis". O Dr. Picoto considerava que só assim se poderia convencer habitantes locais a melhor aceitar a ciência médica (Picoto, 1963: 67-68). O recurso à pluralidade terapêutica pelas populações africanas ao longo do jugo português no território foi demonstrado por Redinha, afirmando que tal situação acontecia também no Chitato (Redinha, 1975: 347-361).

Mesmo considerando o viés inerente a factores como a geografia produtiva regional, a relação com a empresa e os caracteres rácicos, a acção dos SSD não tinha paralelo em Angola entre os serviços de saúde estatais, outras grandes companhias, como a Caminhos de Ferro de Benguela e Cassequel, nem entidades privadas de menor dimensão (Esteves, 1999: 582- 592; Ball, 2003: 233). Estas comparações reforçam a impressão muito positiva tida pelo governo dos SSD. Na visita oficial de 1945, o Ministro das Colónias Marcelo Caetano louvou as condições de vida e de trabalho propiciadas pela companhia, notando com particular atenção os cuidados médicos dispensados em prol da 'saúde da população indígena'.

\section{A calma aparente no olho do furacão: 1957-1974}

Neste último período, o SSD prosseguiu com a ocupação sanitária da Lunda, com o desiderato de abranger toda a população do Chitato. Apesar de apresentar mais infra-estruturas e atenção na prestação de cuidados de saúde aos vários segmentos populacionais, a hierarquia na atenção biomédica permanecia activa no Chitato.

Em 1957, o Dr. Santos David substitui o Dr. Picoto como médico-chefe na direcção dos SSD, que entretanto eram (re)classificados como direcção. A área de actuação dos SSD continuava a dilatar com aquiescência do Estado, passando de 40.706 km² em 1957 para $52.000 \mathrm{~km}^{2}$ no final do período colonial. Aumentou também a população durante este terceiro período de quase 80.000 habitantes no final da década de 1950, para cerca de 135.000 no final do período colonial, dos quais somente $3 \%$ eram europeus (Varanda, 2007). 
A esta conjuntura os SSD responderam com um incremento de instalações sanitárias - os hospitais subiram para onze, as maternidades duplicaram e os postos sanitários também aumentaram. No entanto, estas modificações não significavam construção de raiz, mas antes renovações (David, 1965: 24-25). Assim, a maioria das instalações continuavam a ser postos sanitários, pequenos edifícios de baixo-custo (usualmente pré-fabricados), dirigidos por pessoal africano e localizados perto de locais de exploração ou em áreas rurais específicas.

Este aumento levou ao incremento da capacidade de camas. Os SSD passaram de 744 camas em 1957 para mais de 1.500 camas no final do período coIonial, mas longe das 2.720 recomendadas pela Comissão Técnica Inter-Africana (VVA, 1958: 30-94). Face à insuficiência de camas não eram incomuns episódios de sobrelotação ${ }^{33}$ e queixas por parte da direcção dos SSD sobre a qualidade destas ${ }^{34}$. Nos anos 70 o aumento de expatriados, familiares e elementos do exército português conduziram à quebra da 'regra' um quarto um paciente, chegando em 1973 a serem 'hospitaliza-

33 Dra. Palmira Pinhão, entrevista 18/05/2004.

34 Dr. Santos David, "RAS 1960" Serviços de Saúde da Diamang, Companhia de Diamantes de Angola, Dundo, Angola, Dundo, Angola: 27. dos' em $\operatorname{casa}^{35}$ (Tabela 1). A hospitalização partilhada poderia ser considerada como uma situação inconfortável, mas era rotina para os pacientes africanos que desde 1920 experienciavam situações de sobrelotação.

Tabela 1. Número de camas por instalação sanitária entre 1950 e 1970.

\begin{tabular}{|l|r|r|r|r|}
\hline Instalações de Saúde & 1950 & 1957 & 1965 & 1970 \\
\hline Dundo & 99 & & 452 & 261 \\
\hline Sacavula & & & & 264 \\
\hline Fucaúma & 26 & & 66 & 63 \\
\hline Cassanguídi & 104 & & 99 & 102 \\
\hline Andrada & 222 & & 232 & 266 \\
\hline Maludi & 97 & & 98 & 102 \\
\hline Lucapa & & & 73 & 80 \\
\hline Calonda & & & 8 & 72 \\
\hline Lóvua & & & 94 & 93 \\
\hline Canzar & & & 26 & 79 \\
\hline Sombo & 22 & & 25 & 25 \\
\hline Cachimo & 22 & & 21 & 21 \\
\hline Luia & & & 22 & 22 \\
\hline Capaia & & & 16 & 14 \\
\hline Cuango & & & 15 & 58 \\
\hline Total & 592 & 744 & 1247 & 1522 \\
\hline
\end{tabular}

Fonte: Dr. Picoto “AHR 1950“, Dr. David “AHR 1957;1965; 1970“, MAUC

Mas o crescimento dos SSD não teve paralelo no quadro de saúde de pessoal Português. O despoletar da guerra de libertação em 1961 e o desenvolvimento económico verificado na metrópole criou um obstáculo à ida de profissionais de saúde para o Chitato. Enquanto em 1965 o Dr. David notava a falta de 10

35 Dr. David, "RAS 1970":32; Dr. Afonso, "RAS 1973": 45, MAUC. Dito isto, registos orais de ex-enfermeiros locais mostram que 'hospitalização' de expatriados em casa não era incomum. Entrevistas a ex-enfermeiros locais Paulo Caninda 19/11/2004; Antonio Cuassue, 19/11/2004; Armando Nguatje 19/11/2004; João Kakesse 19/11/2004. Bernardo Montaubuleno entrevista 20/11/2004. 
médicos dos 23 que o quadro permitia, uma situação que se replicava entre enfermeiros e pessoal auxiliar africano, oito anos depois a situação permanecia igual, com o Dr. Rocha Afonso a assinalar a falta de 9 médicos num quadro de 25, e das 52 vagas de enfermeiros somente 17 estavam ocupadas. O problema no quadro africano era menor com apenas 90 vagas por preencher das 1.290 existentes, mas esta falta fazia-se sentir em algumas instalações onde eram os guardas que ajudavam os serviços ${ }^{36}$.

Em 1965 estas debilidades afectavam com maior acuidade áreas mineiras (Cuango, Sombo, Camissombo e Capaia) e os serviços (laboratório de análises clínicas e a maternidade do Dundo) que não tinham pessoal suficiente, estando 'quase entregues' a pessoal sem formação superior ${ }^{37}$. Com lucros galopantes a Diamang poderia ter enveredado por outras políticas. Além de providenciar melhores condições para atrair pessoal médico e de enfermagem portugueses, a companhia podia ter quebrado com a discriminação racial nos quadros dos SSD e contratado médicos e enfermeiros diplomados africanos, seguindo a porta aberta pelas reformas políticas de Adriano Moreira, estendendo assim a política de africanização aos quadros superiores dos SSD. Ao invés, as suas políticas raciais

\footnotetext{
36 Dr. Afonso, "RAS 1973": 13-25, MAUC.

37 Dr. David, "RAS 1965": 5, MAUC.
}

mantiveram-se, tentando incrementar o aumento do quadro auxiliar local através da atribuição de bolsas de estudo para agentes sanitários que desejavam prosseguir na sua carreira. Uma solução que segundo Dr. Rocha Afonso comprometia a competência e produtividade dos serviços, e prejudicava a qualidade dos cuidados de saúde prestados, nas áreas urbanas e rurais, bem como nas campanhas móveis que partiam sem supervisão médica ${ }^{38}$. No pós-1961, africanos e portugueses eram iguais perante a lei, no entanto tal não se verificava no acesso aos quadros superiores dos SSD bem como aos cuidados biomédicos. Mais uma vez eram as populações sem relação produtiva com a Diamang que suportariam o peso da 'pirâmide'.

Apesar dos problemas com o pessoal, as estatísticas de assistência revelam números impressionantes ${ }^{39}$. Em 1960 foram contabilizados 2.165 .322 actos de assistência, um valor que, excluindo domingos, perfaz uma média de 210 acções por dia, e ultrapassa as 50 acções por dia da Cassequel (Ball, 2003: 232-233) ou mesmo dos serviços estatais. Em 1968 os SSHA realizaram 8.250.00 de tratamentos para cerca de 1.100 .000 doentes numa população de

\footnotetext{
38 Jorge Viegas nota 6/6/74, Dr. Afonso, "RAS 1973", p.7, MAUC.

39 Apesar de ser difícil estabelecer a definição referente a actos de assistência empregues pelos diferentes actores coloniais, esta comparação em lato senso ilustra a diferença de prestação de cuidados de saúde.
} 
aproximadamente 5.800.00 (Shapiro, 1983: 165-166), enquanto os SSD efectuaram 3.209.182 actos de assistência para uma população de cerca de 100.000 indivíduos.

Estes dados do Chitato reflectem o aumento do número de trabalhadores, aumento da população e um uso crescente por parte de africanos da biomedicina. Esta 'confiança' não quer dizer que o pluralismo médico tivesse desaparecido, mas sim que africanos definiam qual o sistema médico a usar de acordo com o problema de saúde e os resultados previamente experimentados por eles ou outrem (Redinha, 1975; Areia, 1990) ${ }^{40}$.

As análises clínicas efectuadas pelos SSD enfatizam o investimento diferencial colonial e os diferentes conceitos de medicina activos. Embora 85\% das análises pedidas por médicos e/ou efectuadas rotineiramente pelas missões no despiste à tripanossomíase ou tuberculose eram de africanos, os europeus recebiam 13\% das análises laboratoriais, mais uma vez, muito acima da sua representação no bolo populacional de 3\%. Esta situação ganha mais ênfase quando se verifica que as análises mais complexas eram efectuadas para expatriados, restando para a população local exames parasitários ou relacionados com campanhas de despiste específicas ${ }^{41}$. Quanto à saúde oral, era

40 Algo disseminado em vários contextos coloniais, ver Wallace (2002).

41 Dr. David, "RAS 1960"; "RAS 1965"; "RAS 1970",MAUC. um serviço eminentemente desenhado para ocidentais. Em 1960 os empregados e suas famílias recebiam cerca de $74 \%$ de todos os actos de assistência dentária, uma percentagem que aumentou para 83\% em 1970.

Em 1960, o Dr. David notava que as diferenças na prestação de cuidados de saúde às diferentes populações, especialmente para as famílias dos trabalhadores, estavam a desaparecer ${ }^{42}$. Mas a análise a relatórios subsequentes assinados pelo Dr. Santos David revelam que esta ideia era infundada. Os trabalhadores africanos continuavam a ser os indivíduos do pólo africano que recebiam maior atenção por parte dos serviços de saúde, seguidos das suas famílias e ficando em último a população local, i.e. estranhos. Entre 1960 até 1973 a percentagem de Ocidentais operados pelo SSD ascendia a 12\% do número total de operações, embora esta população não atingisse $3 \%$ da população total ${ }^{43}$. O serviço de saúde continuava a direccionar a sua atenção entre africanos para o nicho mais relevante: mão-de-obra ${ }^{44}$. $\mathrm{O}$ viés na prestação de cuidados biomédicos não se modificou.

\footnotetext{
42 Dr. David, "RAS 1960" : 83, MAUC.

43 Dr. Afonso, "RAS 1973": 55, MAUC.

44 Ball nota que nesta década algo similar se passava na empresa de açúcar, mas é imperioso notar as diferenças entre os programas coloniais e contractos com o estado, pois a Cassequel não tinha uma área sob a sua alçada, não tendo assim que provir de cuidados biomédicos à população local (Ball, 2003: 233).
} 
Tabela 2. Comparação da percentagem da população com a percentagem de assistência prestada pelos SSD entre 1965 e 1970.

\begin{tabular}{|l|c|c|c|c|c|c|}
\hline & \multicolumn{3}{|c|}{1965} & \multicolumn{3}{c|}{1970} \\
\hline Categorias & Trabalhadores & Famíliares & Estranhos & Trabalhadores & Famíliares & Estranhos \\
\hline Polulação em Percentagem & $27 \%$ & $32 \%$ & $41 \%$ & $16 \%$ & $41 \%$ & $43 \%$ \\
\hline Volume de Assistência Prestada & $41 \%$ & $27 \%$ & $32 \%$ & $31 \%$ & $37 \%$ & $32 \%$ \\
\hline Diferenças & $14 \%$ & $-5 \%$ & $-9 \%$ & $15 \%$ & $-4 \%$ & $-11 \%$ \\
\hline
\end{tabular}

Fonte: Dr. David "RAS 1965": 84; Dr. Afonso, "RAS 1973":80, MAUC.

Doenças como a malária e as doenças respiratórias (pneumonia, broncopneumonia, tuberculose pulmonar e problemas respiratórios decorrentes da gripe) continuavam a atingir as populações africanas, algumas com a mesma ou maior intensidade que nos anos 20. As parcas acções específicas do SSD para lidar com a malária contribuíram para que em 1973 fosse a principal causa de morbilidade com 27\%. A baixa mortalidade em contraste com outras enfermidades e uma percepção que este era um problema insolúvel, devido à impossibilidade de erradicar o vector, contribuíram para a ausência da aplicação de um programa de combate à malária de forma sistemática ${ }^{45}$.

Os problemas respiratórios permaneciam como a principal causa de mortalidade de africanos. Comparando com a malária ou mesmo com acidentes de trabalho, as doenças respiratórias representavam uma fatia menor nos diagnósticos e hospitalizações, mas contribuindo fortemente para serem a principal causa de morte de africanos com

45 Dr. David, "RAS 1960": 87. Dr. David, "RAS 1965": 113; Dr. Afonso, "RAS 1973": 85-86, MAUC.
30\% dos hospitalizados a falecerem ${ }^{46}$. Havia, no entanto, casos de sucesso com melhorias das condições de saúde e redução evidente da incidência de problemas de saúde. Endemias consideradas como "tropicais", como a ancilostomíase, bilharziose e outros problemas intestinais representavam nos anos de 1960 cerca de 1\% dos diagnósticos, um valor extremamente baixo quando comparado com a situação experienciada até à década de 50. Numa situação similar estavam as doenças venéreas como a gonorreia e a sífilis, que se mantiveram perto dos 1\% nas décadas de 60 e 70, longe das percentagens de décadas anteriores. Doenças como a varíola, a parotidite e a coqueluche ou tosse convulsa atingiam valores residuais de 0,1\% nos últimos anos do projecto colonial. A vigilância sanitária regular iniciada nos anos 40 nas áreas industrial com o intuito último de aumento da produtividade e o contributo das inspecções da DGL e SSD e consequentes acções ao longo das décadas junto dos chefes-de-mina tinham

46 Ibid. 
claramente contribuído para o decréscimo dos problemas de saúde ${ }^{47}$.

Esta situação era ainda mais tangível na prestação de cuidados biomédicos entre expatriados e africanos. A medicina de enclave pode ter sido quebrada, terem sido implementadas acções preventivas no mato, mas no final do período colonial persistia a complexidade hierárquica colonial. Os empregados da Diamang eram os maiores beneficiários, seguidos pelos trabalhadores africanos, as suas famílias e por último os estranhos. Este investimento diferencial no pólo nativo da equação colonial (ocidentais-africanos) ilustra a economia política da prestação de cuidados biomédicos activa sob a companhia. A protecção da sua força de trabalho africana e seus familiares influenciavam, directa ou indirectamente, a produtividade, havendo assim necessidade de matizar a transferência dos custos de saúde, uma preocupação que não era dominante na relação entre a companhia e os estranhos.

\section{Conclusão}

Inicialmente a Diamang centrou as suas atenções nos ocidentais, somente as grandes perdas na força de trabatho e consequente receio de perda de

47 Dr. David, "RAS 1960": 83, 92-93; "RAS 1965": 118, 131, 133,MAUC. produtividade forçaram-na a atentar a saúde dos trabalhadores das explorações mineiras. No entanto os SSD não apresentavam condições necessárias para tal objectivo. Factores como a parca ocupação colonial anterior à da companhia e a falta de recursos humanos com formação específica na área da saúde fizeram com que entre 1917-1933 a companhia não cumprisse o desiderato contractual de prestação de cuidados biomédicos na área sob sua administração. Nesta fase os seus esforços centraram-se nas zonas urbanas e explorações mineiras. A acção dos serviços focava-se eminentemente nas instalações da companhia (espaços urbanos, industriais e minas), prestando particular atenção a empregados e, quando necessário, a trabalhadores. Este modus operandi enquadra-se no conceito de 'medicina de enclave' apresentado por Arnold.

A reorganização dos dois ramos dos serviços de saúde em 1934 impeliu o alargamento do raio de acção dos serviços conseguido através de missões de saúde móveis e criação de novas instalações. A reforma forçou também a expansão do quadro de pessoal de saúde, realizada através da contratação de médicos e enfermeiros portugueses e a formação local de africanos como auxiliares de saúde. A nível metodológico os programas ambulatórios sofreram grandes alterações: desenvolveram-se 
de forma mais sistemática, perderam o cariz híper-vertical exclusivo para a doença do sono, e com o incremento de pessoal africano adoptou-se uma interacção menos impositiva, logo mais frutuosa, com as autoridades tradicionais. No entanto, a maioria dos problemas sanitários - malária, doenças respiratórias e intestinais, acidentes de trabalho - persistiram. Dito isto, o investimento no combate à doença do sono contribui para a eliminação desta enfermidade na sua área no início da década de 60 (Varanda, 2009).

Somente no final da década de 50 é que os SSD cumpriam com o contrato inicial de prestação de cuidados de saúde em toda a área e a todas as populações. As populações das áreas rurais da Lunda recebiam menos atenção por parte da divisão médica da companhia devido ao cariz centralizado inerente ao sistema de saúde da Diamang, bem como aos problemas sentidos pelos serviços médicos neste terceiro período, nomeadamente, a falta de pessoal e a necessidade de manter uma cada vez maior mão-de-obra saudável. Esta situação é verificável através da análise das estatísticas de morbilidade e mortalidade. Mesmo no crepúsculo colonial, o número de mortes por doenças evitáveis em famílias africanas e nomeadamente estranhos revela que, apesar de a companhia apresentar um elevado número de instalações e cam- panhas ambulatórias, ainda havia muito 'caminho a percorrer' para se atingir a equidade nos tratamentos de saúde.

A economia política da prestação de biomedicina persistia tendo como consequência a manutenção da hierarquia de cuidados. Esta hierarquia revela que a par da apropriação pela Diamang do domínio da produção de discursos e representações coloniais sobre africanos, a companhia estava consciente de que existiam diferenças entre africanos, enfatizando-se assim um sistema classificatório que ia além da questão rácica e que tinha como base a capacidade produtiva e afiliação para consigo. Desde os anos de 1920 até 1973 nos SSD a prestação de cuidados biomédicos era efectuada segundo a classificação da Diamang, baseada na afiliação dos indivíduos à companhia. Para os europeus as várias classificações existentes (empregados, familiares e estranhos) reproduziam-se num único tipo de práticas terapêuticas. No caso dos africanos, embora as classificações fossem semelhantes (trabalhadores, familiares e estranhos), havia um acesso diferencial aos cuidados biomédicos de acordo com a área geográfica nos quais estes laboravam ou habitavam, mas também uma prestação produtiva diferencial face ao seu estatuto classificatório dentro da companhia. Os trabalhadores recebiam mais cuidados biomédicos ajudando assim a proteger a produção diamantífera, 
os seus familiares eram também alvo de atenção para colmatar a transferência indirecta dos custos de saúde, ficando na base da pirâmide os estranhos, i.e., a população local que não tinha relações

Na resposta de Vilhena às considerações de Gilberto Freyre sobre a Diamang presentes no Aventura e rotina, o administrador-delegado defendia que a com-

panhia não tinha práticas racistas, pois todos eram tratados de igual modo sob a égide do tradicional 'cuidado fraternal Português'. No entanto, nos interstícios das palavras e letras da sua resposta estava a realidade do terreno onde uns eram tratados como filhos, alguns como enteados e outros como apadrinhados.

\section{Referências bibliográficas}

Addae, S. 1996. History of Western Medicine in Ghana, 1880-1960, Edinburgh, Durham Academic Press.

Areia, M. L. R. 1990. Contribution to the study of cultural dualism in medical practices. In: Chaudhuri, B. (ed.). Cultural and environmental dimension on health. Delhi, Inter-India publications: 124-130.

Arnold, D. 1993. Colonizing the body - state medicine and epidemic disease in nineteenth-century India. Berkeley, University of California Press.

Balandier, G. 1955. "La notion de 'situation coloniale'"In: Balandier, G. (ed.). Sociolo-

gie actuelle de L'Afrique noire, dynamique des changements sociaux en Afrique Centrale. Paris, Presses Universitaires de France.

Ball, J. 2003. "The colossal lie": the Sociedade Agrícola do Cassequel and Portuguese colonial labor policy in Angola, 18991977. Doctoral Dissertation, University of California.

Bell, H. 1999. Frontiers of medicine in the Anglo-Egyptian Sudan, 1899-1940. Oxford, Clarendon Press.

Carstens, P. 2001. In the company of diamands - De Beers, Kleinzee, and the control of a town. Athens, Ohio University Press.

Castelo, C. 1998. "O Modo Português de estar no Mundo", O luso-tropicalismo e a ideologia colonial portuguesa (1933-1961). Porto, Edições Afrontamento.

Cleveland, T. 2008. Rock solid: african laborers on the diamond mines of the companhia de diamantes de Angola (Diamang), 1917-1975. Doctoral Dissertation, University of Minnesota.

David, J.M.S. 1965. Alguns aspectos da assistência médico-sanitária no concelho do Chitato (Luanda, Agola). Lisboa, Companhia de Diamantes de Angola.

Esteves, E. 1999. O caminho de ferro de Benguela e o impacto econômico, social e cultural na sua zona de influência 1902-1952. Tese de Doutoramento, Universidade do Porto.

Freyre, G. 1954. Aventura e rotina: sugestões de uma viagem à procura das constantes portuguesas de carácter e acção. Lisboa, Livros do Brasil. 
Forminière. 1956. Forminière - 1906-1955. Bruxelles, Les Editions L. Cypres.

Hunt, N. R. 1999. A Colonial lexicon - of birth ritual, medicalization and mobility in the Congo. Durham, Duke University Press.

Lyons, M. 1991. The colonial disease - a social history of sleeping sickness in Northern Zaire, 1900-1940. Cambridge, Cambridge University Press.

Packard, R. 1987. Tuberculosis and the development of industrial health policies on the Witwatersrand, 1902-1932. Journal of Southern African Studies, 13(2): 187209.

Packard, R. 1989. White plague, black labourtuberculosis and the political economy of health and disease in South Africa. Berkeley, CA, University of California Press.

Packard, R. 1993. The invention of the 'Tropical Worker': medical research and the quest for central African labor on the South African gold mines, 1903-36. The Journal of African History, 34(2): 271-292.

Parkinson, L. J. 1962. Memoirs of African Mining. s/ed.

Pélissier, R. 1986. História das campanhas de Angola. Resistência e revoltas 1845-1941. 2 vols. Lisboa, Estampa.

Perrings, C. 1977. 'Good lawyers but poor workers': recruited Angolan labour in the copper mines of Katanga, 19171921. The Journal of African History, 18(2): 237-259.

Perrings, C. 1979. Black mineworkers in Central Africa. Industrial strategies and the evolution of an African proletariat in the copperbelt, 1911-1941. London, Heinemann Educational Books.

Porter, D. 2005 [1999]. Health, civilisation and the state: a history of public health from antiquity to modernity. London, Routledge.

Picoto, J. 1963. Uma accão médico-sanitária em áfrica altamente dignificante para Portugal; Assistência médicosanitária na Lunda pela Companhia de Diamantes de Angola. Separata do Jornal do Médico, Porto, 11(51): 66-78.

Porto, N. 2002. O museu e o arquivo do império (o terceiro império português visto do Museu do Dundo. In: Bastos, C.; Vale de Almeida, M.; Feldman-Bianco, B. (eds.). Trânsitos coloniais: diálogos críticos luso-brasileiros. Lisboa, Imprensa de Ciências Sociais: 117-132.

Porto, N. 2009. Modos de objectificação da dominação colonial: o caso do Museu do Dundo, 1940-1970. Lisboa, Fundação Calouste Gulbenkian/Fundação para a Ciência e a Tecnologia.

Prakash, G. 1994. Subaltern studies as postcolonial criticism. American Historical Review, 99(5): 1475-1490.

Redinha, J. 1975. Etnias e culturas de Angola. Luanda, Instituto de Investigação Científica de Angola.

Ross, E. A. 1925. Report on the employment of native labor in Portuguese Africa. New York, The Abbott Press.

Shapiro, M. F. 1983. Medicine in the service of colonialism: medical care in Portuguese Africa, 1885-1974. Doctoral Dissertation. University of California. 
Stoler, A. L. 2009. Along the archival grain epistemic, anxieties and colonial common sense. New Jersey, Princeton University Press.

van Onselen, C. 1976. Chibaro: African mine labour in Southern Rhodesia 1900-1933. Johannesburg, Ravan Press.

Varanda, J. 2007. 'A Bem da Nação': medical science in a diamond company in twentieth-century colonial Angola. Doctoral Dissertation, University College London.

Varanda, J. 2009. Um cavalo de Tróia na colónia? Missões de profilaxia contra a doença do sono da Diamang. In: Pereira, L. S.; Pussetti, C. (eds.) Os Saberes da cura, antropologia da doença e práticas terapêuticas. Lisbon, ISPA/CEAS.

Varanda, J. 2010. Crossing colonies and empires: the health services of the diamond company of Angola. In: Digby, A.; Ernst, W.; Muhkarji, P. B. (eds.). Crossing colonial historiographies: histories of colonial and indigenous medicines in transnational perspective. Cambridge, Cambridge Scholars Publishing: 165-184.

Varanda, J. 2011. A asa protectora de outros: as relações transcoloniais do Serviço de Saúde da Diamang. In: Bastos, C.; Renilda, B. (eds.). Circulação do conhecimento médico: medicina, redes e impérios. Lisbon, ICS: 339-373.

Vaughan, M. 1991. Curing their IIIs: Colonial Power and African IIIness. Palo Alto: Stanford University Press.

Vilhena, E. 1955. Aventura e rotina (crítica de uma crítica). Lisboa, s/ed.
VVA, 1958. Bulletin. Comissão Tecnica Inter-Africana. vol. V(3), London.

Wallace, M. 2002. Health and society in Widhoek, Namibia, 1915-1945. Basel, P. Schlettwien Publishing.

\section{Fontes primárias e entrevistas}

\section{Arquivo da Diamang - Museu Antropológico da Universidade de Coimbra (MAUC)}

\section{Pastas do Serviços de Saúde da Diamang}

Pasta Direcção Administrativa - Serviço de Saúde, Relatórios Mensais - Agosto/1926 - Dezembro/1931.

Pasta 126B,5-10, MPDS, 4/1/22 - 31/10/33.

Pasta 126B,9-40, Serviços de Saúde (Relatórios Médicos) de 1/8/33 - 30/9/37.

Pasta 126B,9-6.

Pasta 126B,9-10.

Dr. David, Relatório Anual de Saúde de 1960, Serviços de Saúde da Diamang, Companhia de Diamantes de Angola, Dundo, Angola, 1960.

Dr. David, Relatório Anual de Saúde de 1965, Serviços de Saúde da Diamang, Companhia de Diamantes de Angola, Dundo, Angola,1965.

Dr. David, Relatório Anual de Saúde de 1970, Serviços de Saúde da Diamang, Companhia de Diamantes de Angola, Dundo, Angola, 1970. 
Dr. Afonso, Dr. David, Relatório Anual de Saúde de 1973, Serviços de Saúde da Diamang, Companhia de Diamantes de Angola, Dundo, Angola, 1973.
Pasta 84K3-40, "Ocupação e Diversos," de $1 / 8 / 23-30 / 11 / 23$.

BDR 1946: 9.

BOA (Boletim Oficial de Angola), nº 43 II serie, 27 de Outubro, SGL.

Outras pastas e documentos

\begin{tabular}{|c|c|c|c|}
\hline \multicolumn{4}{|l|}{ Entrevistas } \\
\hline & $\begin{array}{l}\text { Data da } \\
\text { Entrevista }\end{array}$ & $\begin{array}{l}\text { Relação do Entrevistado } \\
\text { com Diamang }\end{array}$ & $\begin{array}{l}\text { Local } \\
\text { da Entrevista }\end{array}$ \\
\hline \multicolumn{4}{|l|}{ Em Angola } \\
\hline Bernardo Montaubuleno & $20 / 11 / 2004$ & Enfermeiro & Dundo \\
\hline Teresa Penedo & $16 / 11 / 2004$ & $\begin{array}{l}\text { Enfermeira, trabalhou nas } \\
\text { Missões das Grávidas }\end{array}$ & Dundo \\
\hline Paulo Caninda & $19 / 11 / 2004$ & Ex-Enfermeiro dos SSD & Dundo \\
\hline Antonio Cuassue & $19 / 11 / 2004$ & Ex-Enfermeiro dos SSD & Dundo \\
\hline Armando Nguatje & $19 / 11 / 2004$ & Ex-Enfermeiro dos SSD & Dundo \\
\hline João Kakesse & $19 / 11 / 2004$ & Ex-Enfermeiro dos SSD & Dundo \\
\hline \multicolumn{4}{|l|}{ Em Portugal } \\
\hline Dra. Palmira Pinhão & $18 / 05 / 2004$ & & Oeiras \\
\hline Albuquerque & $15 / 12 / 2004$ & Médico-veterinário & Coimbra \\
\hline Dr. Santos David & $27 / 01 / 2004$ & $\begin{array}{l}\text { Médico, Chefe dos SSD } \\
\text { e do Gabinete de Antropologia }\end{array}$ & Estoril \\
\hline
\end{tabular}

